Research Paper

\title{
The use of ultrasonic scalpel lowers the risk of post- mastectomy seroma formation in obese women
}

\author{
Tomasz Michalik¹, Rafal Matkowski ${ }^{1,2}$, Przemyslaw Biecek ${ }^{3}$, Bartlomiej Szynglarewicz ${ }^{1,2 \llbracket}$ \\ 1. Breast Unit, Lower Silesian Oncology Center - Regional Comprehensive Cancer Center, Plac Hirszfelda 12, 53-413 Wroclaw, Poland \\ 2. Department of Oncology, Faculty of Postgraduate Medical Training, Wroclaw Medical University, Plac Hirszfelda 12, 53-413 Wroclaw, Poland \\ 3. Faculty of Mathematics and Information Science, Warsaw University of Technology, Koszykowa 75, 00-662 Warsaw, Poland \\ $\square$ Corresponding author: Dr. Bartlomiej Szynglarewicz, Associate Professor, Department of Oncology, Wroclaw Medical University, Department of Surgical \\ Oncology, Lower Silesian Oncology Center - Regional Comprehensive Cancer Center, Plac Hirszfelda 12, 53413 Wroclaw, Poland. E-mail: \\ szynglarewicz.b@dco.com.pl; phone: +48 071 3689391; fax: +48 0713619111 \\ (1) Ivyspring International Publisher. This is an open access article distributed under the terms of the Creative Commons Attribution (CC BY-NC) license \\ (https://creativecommons.org/licenses/by-nc/4.0/). See http://ivyspring.com/terms for full terms and conditions.
}

Received: 2018.09.07; Accepted: 2019.04.05; Published: 2019.06.09

\begin{abstract}
Introduction: Seroma formation (SF) is the most common postoperative complication after mastectomy and axillary surgery. The aim of this study was to assess its incidence and risk factors following a modified radical mastectomy in breast cancer patients.

Materials and methods: 271 patients who underwent a modified radical mastectomy ( 250 with traditional electrocautery and 21 with an ultrasonic scalpel) were studied. The SF rate was calculated and its association with patient-related factors, surgical features and postoperative variables was assessed and statistically analyzed with $P<0.05$ as a significance threshold.

Results: SF was observed in $18 \%$ of patients. Patient's age, operating time and number of removed axillary lymph nodes did not significantly differ between SF and non-SF patients. Patients BMI, total drainage amount, number of days with drain were higher and postoperative hospital stay was significantly longer in SF patients $(P<0.001$ each). The dissection instrument was also an important risk factor: SF developed in $20 \%$ of patients operated with electrocautery and in none with an ultrasonic scalpel $(P<0.05)$. The association between surgical instrument and the number of removed lymph nodes, patient's age and BMI was not significant. Dissection with an ultrasonic scalpel resulted in a statistically significant lower total drainage amount. However, it was also related to a significantly longer operating time $(P<0.001$ each).

Conclusions: Risk of SF after a modified radical mastectomy is significantly higher in patients with obesity. Despite longer operating time, using an ultrasonic scalpel is a valuable option in those cases because it lowers the total drainage amount and seems to be an important protective factor against SF.
\end{abstract}

Key words: Breast cancer, Mastectomy, Seroma formation, Obesity, Ultrasonic scalpel

\section{Introduction}

In the era of screening programs and oncoplastic surgery, women with breast cancer undergo breast conserving therapy and achieve good cosmetic results without compromising the oncological outcomes [1-6]. However, modified radical mastectomy remains a reasonable surgical option in some cases, such as patients with extensive breast disease and metastatic lymph nodes.
Seroma formation (SF), defined as serous fluid collection under skin flaps or in the axillary dead space, is the most common postoperative complication after mastectomy and axillary surgery; developing in up to $90 \%$ of patients [7]. Some claim that it is almost inevitable, being rather a sequel than a complication of breast surgery [7-10]. Although SF is so common, its pathogenesis has not been elucidated enough and no satisfactory therapy is yet available 
[11]. Persistent SF and inadequate drainage can be a source of physical and psychological morbidity to the patient in the postoperative period and may lead to infection, flap necrosis, wound dehiscence, a prolonged recovery period, hospitalization and a delay in adjuvant treatment [9-11].

The primary aim of this study was to evaluate the risk factors of SF and their incidence following a modified radical mastectomy. The secondary aim was to compare, in respect to the variables associated with SF formation, groups of patients operated on using different surgical instruments: standard electrocautery (EC) and an ultrasonic scalpel (US).

\section{Material and Methods}

\section{Patients}

Two hundred seventy one patients surgically treated in our department in the years 2004-2017 entered the analysis after fulfilling the inclusion criteria. These included cT1-T3N1 breast cancer histologically diagnosed on minimal-invasive breast biopsy, no preoperative therapy or prior surgery of ipsilateral breast, no modified radical mastectomy because of multicentric or extensive cancer with an unfavorable ratio of lesion size to breast volume, no immediate reconstruction, negative margins in postoperative examination, and no immunological or coagulation disorders.

\section{Surgery}

After full informed consent was obtained, a modified radical mastectomy with axillary dissection, without transection of the pectoralis minor, according to the technique reported by Auchincloss, was performed in all patients. In 250 patients the dissection was done with EC using a monopolar electrode (ERBE, VIO 300D). 21 women were operated on using an US with a constant frequency of $55.5 \mathrm{kHz}$ and a $75 \mu \mathrm{m}$ (level 3) longitudinal extension of the vibration (Ultracision, Ethicon Endo-Surgery Europe). According to our department policy, a single pectoro-axillary silicone drain was placed before skin closure. The use of several separate drains was avoided to reduce patient discomfort and decrease the risk of postoperative complications. A closed suction drainage system (Jackson-Pratt) was used. The drain was routinely placed through the lower skin flap at the anterior axillary line and held in-place with a stitch to prevent an accidental slip out and vacuum loss. The drain was removed when its output was equal to or less than $50 \mathrm{~mL}$ in 24 hours, irrespective of the drainage duration. In case of a greater drainage amount the drain was removed after a maximum of five days in order to protect against surgical site infection. Typically, patients were discharged the day after the drain removal and referred to the outpatients clinic. Postoperative wound care was managed by a certified surgery-dedicated nurse. All patients were informed about the normal changes occurring after a mastectomy as well as the possible complications that may occur. The schedule of control visits was adjusted on an individual basis by the surgical nurse depending on the state of the wound and the healing process. Seroma was regarded to be present if a clinically evident serous fluid collection, requiring aspiration, was found at the operating site.

\section{Statistical analysis}

Data was collected and entered into a computer database. The median, mean, standard deviation, and range were calculated for the analyzed variables. The incidence of SF was calculated. Association of SF rate and pre- (patients age and BMI), peri- (dissection instrument, operating time, number of removed lymph nodes), and postoperative factors (total drainage amount, number of days with drain, postoperative hospital stay) was evaluated. Then the comparison between patients operated with EC and an US scalpel was performed. Categorical variables were analyzed using a Pearson's chi-square test while continuous variables were analyzed with a Mann-Whitney U-test and a Kruskal-Wallis test. $P$-values less than 0.05 were considered statistically significant.

\section{Results}

Median (range, mean \pm SD) age of patients was 55 years $(32-79,55.3 \pm 11.3)$ while BMI was 24 (19-36, $24.4 \pm 3.9)$. Operating time, number of removed lymph nodes and total drainage amount were: 65 minutes (30-130, $69.8 \pm 25.3), 15(11-29,15.7 \pm 0.9)$, and $160 \mathrm{~mL}$ (80-350, $176.2 \pm 74.9$ ), respectively.

SF was observed in $18 \%$ of patients $(49 / 271)$. Patients in non-SF group were younger, but without statistical importance (median, range, mean \pm SD): 55 , $32-79,54.7 \pm 11.8$ vs $61,52-65,59.2 \pm 5.1$ years $(P=0.41)$, respectively. Patients BMI was significantly higher in SF group: $32,28-36,32.2 \pm 3.0$ vs $23,19-30,23.4 \pm 2.7$ $(P<0.001)$, respectively. Among 229 patients without obesity $(B M I<30)$ SF was found in $4 \%$ of cases $(n=9)$ while in $95 \%(n=40)$ of obese patients $(P<0.0001)$. Operating time was similar in SF and non-SF groups: $65,40-128,70.4 \pm 24.5$ vs $60,30-125,69.5 \pm 26.6$ minutes $(P=0.85)$, respectively. Number of removed lymph nodes did not significantly differ: $14,11-29,14.4 \pm 1.8$ vs $15,12-27,15.6 \pm 1.7(P=0.18)$, respectively.

SF developed in $20 \%$ of patients $(49 / 250)$ operated with EC and in none $(0 / 21)$ operated with US $(P<0.05)$. Total drainage amount was significantly 
lower in non-SF group: $150,80-290,158.5 \pm 60.6$ vs 310 , 290-350, $312 \pm 17.9 \mathrm{~mL}(P<0.001)$, respectively. 104 patients, including all of the 49 with SF, had a total drainage amount higher than $200 \mathrm{~mL}$. The difference was important when compared to 167 patients with a lower drainage amount $(P<0.001)$. All SF patients had a drain for 5 days while their postoperative hospital stay was 6 days. Both periods were significantly longer than in the non-SF group, where the number of days with a drain and the postoperative hospital stay was: $3,2-5,3.15 \pm 0.7$ days $(P<0.001)$, and $4,3-6,3.5 \pm$ 0.8 days $(P<0.001)$, respectively. Results are presented in Table 1.

Table 1. Association between seroma formation (SF) and clinical variables

\begin{tabular}{|c|c|c|c|}
\hline Variable & non-SF group & SF group & $P$-value \\
\hline \multicolumn{4}{|l|}{ Age (years) } \\
\hline median / range & 55 / 32-79 & $61 / 52-65$ & 0.41 \\
\hline$\leq 60 />60$ & $146 / 76$ & $31 / 18$ & 0.74 \\
\hline \multicolumn{4}{|l|}{ BMI } \\
\hline median / range & 23 / 19-30 & 32 / 28-36 & $<0.001$ \\
\hline$<30 / \geq 30$ & $220 / 2$ & $9 / 40$ & $<0.0001$ \\
\hline \multicolumn{4}{|l|}{ Number of lymph nodes } \\
\hline median / range & 14 / 11-29 & 15 / 12-27 & 0.18 \\
\hline$\leq 15 />15$ & 119 / 103 & $23 / 26$ & 0.56 \\
\hline \multicolumn{4}{|l|}{ Surgical device } \\
\hline electrocautery / ultrasonic scalpel & $201 / 21$ & $49 / 0$ & $<0.05$ \\
\hline \multicolumn{4}{|l|}{ Operating time (minutes) } \\
\hline median / range & $60 / 30-125$ & $65 / 40-130$ & 0.85 \\
\hline \multicolumn{4}{|l|}{ Total drainage amount $(\mathrm{mL})$} \\
\hline median / range & $150 / 80-290$ & $310 / 290-350$ & $<0.001$ \\
\hline$\leq 200 />200$ & $167 / 55$ & $0 / 49$ & $<0.001$ \\
\hline \multicolumn{4}{|l|}{ Number of days with drain } \\
\hline median / range & $3 / 2-5$ & $5 / 5-5$ & $<0.001$ \\
\hline \multicolumn{4}{|l|}{ Postoperative hospital stay (days) } \\
\hline median / range & $4 / 3-6$ & $6 / 6-6$ & $<0.001$ \\
\hline
\end{tabular}

Neither patients age nor BMI significantly differed between patients operated with EC and an US: $56.5,32-79,56.4 \pm 11.9$ vs $54.5,34-78,54.5 \pm 10.8$ years $(P=0.47)$, and $24,19-35,24.3 \pm 3.8$ vs $24,19-36$, $24.4 \pm 4.0 \quad(P=0.96)$, respectively. The association between the dissecting instrument and the number of removed lymph nodes was also not important: 15, $12-29,15.4 \pm 1.3$ vs $15,11-28,15.5 \pm 1.7(P=0.23)$, respectively. Dissection with an US resulted in significantly lower total drainage amount: 100, 80-130, $98.6 \pm 17.1$ vs $220,150-350,232.8 \pm 59.1(P<0.001)$, respectively. None of these patients had a total drainage amount higher than $200 \mathrm{~mL}$, compared to $55 \%$ of patients operated with EC who did $(P<0.05)$. However, the operating time was significantly longer when US was used: $120,110-130,119.8 \pm 6.6$ vs 65 , 30-105, $63.8 \pm 19.1$ minutes $(P<0.001)$, respectively. Comparison is shown in Table 2.

\section{Discussion}

The term seroma suggests that the fluid originates from the ultrafiltration of blood. However, the terms lymphocele and lymphocyst are also used, because lymph leakage from the upper extremity through transected axillary lymph vessels is believed to be an important factor in fluid formation [10]. The reported incidence of SF following breast surgery varies widely between $2.5 \%$ to $90 \%$ [7-11]. Its risk has been reported to be significantly associated with the type of surgery [8-12], breast size [13], number of involved lymph nodes $[13,14]$, tumor size [14] and patient age $[15,16]$. We observed a statistically significant association between obesity and an increased SF rate. Our results are in concordance with several other studies. Lumachi et al reported significantly higher BMI $(26.1 \pm 2.9$ vs $23.2 \pm 2.3$; $\mathrm{p}<0.01$ ) in patients with SF [14]. Zielinski et al demonstrated a significant correlation between obesity (BMI equal or over 30) and higher total seroma volume as well as a longer total time of seroma treatment [15]. Banerjee et al found that in cases with $\mathrm{BMI}<30$ the mean total drainage and the daily drainage were significantly lower when compared to patients with higher BMI [16]. Obesity, affecting more and more people in industrialized countries, is recognized as a major and increasing public health problem which most surgeons will be commonly faced with.

Table 2. Comparison between patients operated with electrocautery and ultrasonic scalpel

\begin{tabular}{llll}
\hline & Electrocautery & Ultrasonic scalpel & $P$-value \\
\hline $\begin{array}{l}\text { Age (years) } \\
\text { median / range }\end{array}$ & $56.5 / 32-79$ & $54.5 / 34-78$ & 0.47 \\
$\leq 60 />60$ & $141 / 109$ & $13 / 8$ & 0.62 \\
BMI & & & \\
median / range & $24 / 19-35$ & $24 / 19-36$ & 0.96 \\
$<30 / \geq 30$ & $213 / 37$ & $16 / 5$ & 0.27 \\
Number of lymph nodes & $15 / 12-29$ & $15 / 11-28$ & 0.23 \\
$\begin{array}{l}\text { median / range } \\
\leq 15 />15\end{array}$ & $124 / 126$ & $11 / 10$ & 0.81 \\
$\begin{array}{l}\text { Operating time (minutes) } \\
\text { median / range }\end{array}$ & $65 / 30-105$ & $120 / 110-130$ & $<0.001$ \\
$\begin{array}{l}\text { Total drainage amount }(\mathrm{mL}) \\
\text { median / range }\end{array}$ & $220 / 150-350$ & $100 / 80-130$ & $<0.001$ \\
$\leq 200 />200$ & $112 / 138$ & $21 / 0$ & $<0.0001$ \\
\hline
\end{tabular}

No single method of preventing SF has been demonstrated to be consistently and reliably effective [11]. However, there are some techniques that have been reported to reduce the incidence of SF and are currently in practice, including mechanical or chemical obliteration of dead space, external compression dressing, delayed shoulder physiotherapy, different drain policies and surgical instruments used for tissue dissection [13]. Among them, an US has been reported to produce less tissue damage than EC because of minimizing the zone of thermal injury [17-19]. A possible association between 
less intraoperative tissue injury and a lower risk of SF is supported by the results of biochemical analyses. Watt-Boolsen et al and McCaul et al found that seroma fluid had a composition different from that of lymph, but similar to that of exudate resulting from an acute inflammatory reaction $[20,21]$.

Just a few studies concerning the usefulness of an US in breast cancer surgery were carried out. Lumachi et al demonstrated in the randomised trial that the use of an US significantly decreased the cumulative amount and duration of drainage after axillary dissection whereas the differences in postoperative hospital stay and office visits were not statistically significant [22]. However, in the larger patient cohort treated in this institution the significant impact of dissection with an US on SF risk was not found, despite the strong association between the total drainage amount and the rate of SF [14]. Deo et al noticed good functional results with an acceptable operating time and a short learning curve for a modified radical mastectomy performed with an US [23]. When compared to EC, a significant reduction of blood loss, total drainage volume and the number of days with drain were observed [24]. Iovino et al randomized and compared patients undergoing breast surgery and axillary dissection using standard scalpel blades, scissors, ligations, EC and an US. They showed a statistically significant benefit in terms of axillary and chest wall drainages, the number of axilla SF, intraoperative bleeding, and hospitalization stay in the US group; without significant differences in operative time [25].

On the contrary, in the series of Galatius et al the use of an US yielded neither clinical advantages nor disadvantages [26]. In the study of Adwani and Ebbs a significant reduction of blood loss was reported for US compared to EC, whereas only a small difference in terms of hospital stay, volume or duration of drainage, and subsequent aspiration of seroma was found [27]. Currie et al in the meta-analysis of 287 mastectomies demonstrated a slightly lower intraoperative blood loss for US compared to EC; while similar results were reported in terms of the total postoperative drainage, operative time, $\mathrm{SF}$ and wound complications [28].

Our study has some important limitations. Firstly, this is a single institution series which may diminish the repeatability of our results in other settings. Secondly, due to the small sample size of the US group, the statistical power of comparison is low. Thirdly, because of the lack of randomization a definitive conclusion cannot be drawn. Moreover, there were three surgeons involved in the operative treatment. Therefore, some surgeon-related factors (learning curve, atraumatic dissection, blood loss, surgery duration, familiarity with an US), even though the surgical protocol was standardized, could influence our findings. In addition, it needs to be kept in mind that it is difficult to interpret our results. The postoperative care following mastectomy can vary considerably among institutions. For example, the drain policy can be completely different in regard to the number of drains, typical drainage duration, number of days or amount of fluid necessary for drain removal etc. There are also other issues that can vary in different countries, for example, the length of the usual postoperative hospital stay or the distribution of control visits after discharge. Furthermore, the drain policy at a particular institution can change overtime resulting in different postoperative management in different time periods at the same institution.

Being aware of these limitations, we believe that our findings may be helpful in the planning of the optimal treatment and improving the patient selection process when the use of new surgical devices is considered. Potential disadvantages of these instruments, such as the high cost and long operative time, need to be balanced by the evidence-based patient benefit.

\section{Conclusions}

Seroma formation can considerably influence patient recovery because it is significantly associated with prolonged drainage and hospital stay. Dissection with an ultrasonic scalpel, despite longer operating time, seems to be an important protective factor against seroma formation. It significantly lowers the total drainage amount, probably by minimizing thermal tissue injury. Consequently, this surgical technique may be considered a valuable option in high-risk cases, particularly in patients with obesity.

\section{Abbreviations}

SF: Seroma formation; BMI: Body mass index; EC: Electrocautery; US: Ultrasonic scalpel.

\section{Acknowledgements}

Authors would like to thank Mr Jacob Bronowicki for his kind assistance in revising the English of this manuscript.

\section{Ethics approval}

The study was conducted in accordance with the Declaration of Helsinki. The institutional review board reviewed and approved the study.

\section{Funding}

This study was financed through a statutory subsidy by the Minister of Science and Higher Education as a part of the research grant 
SUB.C280.19.050 (record number in the Simple System).

\section{Authors' contribution}

TM and BS conceived the study. TM collected and interpreted data. RM and BS carried out the literature research. BS wrote the manuscript. PB performed statistical analysis. RM supervised the composition of the paper and revised it critically for important intellectual content. All authors read and approved the final manuscript.

\section{Competing Interests}

The authors have declared that no competing interest exists.

\section{References}

1. Silvestein MJ, Savalia N, Khan $\mathrm{S}$, et al. Extreme oncoplasty: breast conservation for patients who need mastectomy. Breast J. 2015; 21: 52-9.

2. Clough KB, Lewis JS, Couturaud B, et al. Oncoplastic techniques allow extensive resections for breast-conserving therapy of breast carcinomas. Ann Surg. 2003; 90: 26-34

3. Fitzal F, Gnant M. Breast conservation: evolution of surgical strategies. Breast J. 2006; 12: S165-73.

4. Anderson BO, Masetti R, Silverstein MJ. Oncoplastic approaches to partial mastectomy: an overview of volume-displacement techniques. Lancet Oncol. 2005; 6: 145-57.

5. Szynglarewicz B, Maciejczyk A, Forgacz J, et al. Breast segmentectomy with rotation mammoplasty as an oncoplastic approach to extensive ductal carcinoma in situ. World J Surg Oncol. 2016; 14: 72.

6. Matkowski R, Szynglarewicz B, Kasprzak P, et al. Batwing mastopexy as oncoplastic surgical approach to periareolar tumors in upper quadrants. Tumori. 2012; 98: 421-7.

7. Nadkarni MS, Rangole AK, Sharma RK, et al. Influence of surgical technique on axillary seroma formation: a randomized study. ANZ J Surg. 2007; 77: 385-9.

8. Hashemi E, Kaviani A, Najafi M, et al. Seroma formation after surgery for breast cancer. World J Surg Oncol. 2004; 2: 44.

9. Srivastava V, Basu S, Shukla VK. Seroma formation after breast cancer surgery: what we have learned in the last two decades. J Breast Cancer. 2012; 15: 373-80.

10. Kuroi K, Shimozuma K, Taguchi T, et al. Pathophysiology of seroma in breast cancer. Breast Cancer. 2005; 12: 288-93

11. Agrawal A, Ayantunde AA, Cheung KL. Concepts of seroma formation and prevention in breast cancer surgery. ANZ J Surg. 2006; 76: 1088-95.

12. Gonzalez EA, Saltzstein EC, Riedner CS, et al. Seroma formation following breast cancer surgery. Breast J. 2003; 9: 385-8.

13. Pogson CJ, Adwani A, Ebbs SR. Seroma following breast cancer surgery. Eur J Surg Oncol. 2003; 29: 711-7.

14. Lumachi F, Brandes AA, Burelli P, et al. Seroma prevention following axillary dissection in patients with breast cancer by using ultrasound scissors: a prospective clinical study. Eur J Surg Oncol. 2004; 30: 526-30.

15. Zielinski J, Jaworski R, Irga N, et al. Analysis of selected factors influencing seroma formation in breast cancer patients undergoing mastectomy. Arch Med Sci. 2013; 9: 86-92.

16. Banerjee D, Williams EV, Ilott $\mathrm{J}$, et al. Obesity predisposes to increase drainage following axillary node clearance: a prospective audit. Ann R Coll Surg Engl. 2001; 83: 268-71.

17. Koch C, Friedrich $\mathrm{T}$, Metternich F, et al. Determination of temperature elevation in tissue during the application of the harmonic scalpel. Ultrasound Med Biol. 2003; 29: 301-9.

18. Diamantis $\mathrm{T}$, Kontos $\mathrm{M}$, Arvelakis $\mathrm{A}$, et al Comparison of monopolar electrocoagulation, bipolar electrocoagulation, Ultracision, and Ligasure. Surg Today. 2006; 36: 908-13.

19. Phillips CK, Hruby GW, Durak E, et al. Tissue response to surgical energy devices. Urology. 2008; 71: 744-8.

20. Watt-Boolsen S, Nielsen VB, Jensen J, et al. Postmastectomy seroma. A study of the nature and origin of seroma after mastectomy. Dan Med Bull. 1989; 36: 487-9.

21. McCaul JA, Aslaam A, Spooner RJ, et al. Aetiology of seroma formation in patients undergoing surgery for breast cancer. Breast. 2000; 9: 144-8.

22. Lumachi F, Burelli P, Basso SM, et al. Usefulness of ultrasound scissors in reducing serous drainage after axillary dissection for breast cancer: a prospective randomized clinical study. Am Surg. 2004; 70: 80-4.

23. Deo SV, Shukla NK. Modified radical mastectomy using harmonic scalpel. J Surg Oncol. 2000; 74: 204-7.
24. Deo SV, Shukla NK, Asthana S, et al. A comparative study of modified radical mastectomy using harmonic scalpel and electrocautery. Singapore Med J. 2002; 43: 226-8.

25. Iovino F, Auriemma PP, Ferraraccio F, et al. Preventing seroma formation after axillary dissection for breast cancer: a randomized clinical trial. Am J Surg. 2012; 203: 708-14.

26. Galatius $\mathrm{H}$, Okholm M, Hoffmann J. Mastectomy using ultrasonic dissection: effect on seroma formation. Breast. 2003; 12: 338-41.

27. Adwani A, Ebbs SR. Ultracision reduces acute blood loss but not seroma formation after mastectomy and axillary dissection: a pilot study. Int J Clin Pract. 2006; 60: 562-4

28. Curie A, Chong K, Davies GL, et al. Ultrasonic dissection versus electrocautery in mastectomy for breast cancer - a meta-analysis. Eur J Surg Oncol. 2012; 38: 897-901. 